NASA

Technical Memorandum 87141
USAAVSCOM

Technical Report 86-C-1

\title{
Piezoviscous Effects in Nonconformal Contacts Lubricated Hydrodynamically
}

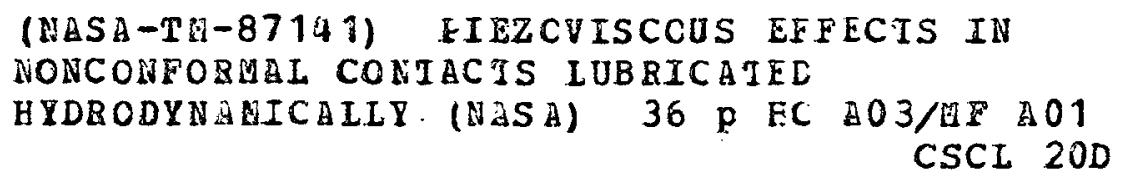

Yeau-Ren Jeng and Bernard J. Hamrock

Lewis Research Center

Cleveland, Ohio

and

David E. Brewe

Propulsion Directorate

U.S. Army Aviation Research and Technology Activity-AVSCOM

Lewis Research Center

Cleveland, Ohio

Prepared for the

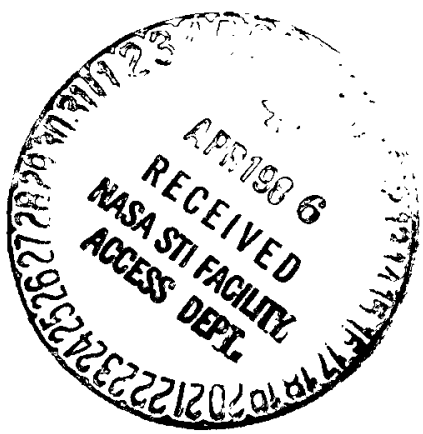

Annual Meeting of the American Society of Lubrication Engineers Las Vegas, Nevada, May 5-9, 1985 


\title{
PIEZOVISCOUS EFFECTS IN NONCONFORMAL CONTACTS LUBRICATED HYDRODYNAMICALLY
}

\author{
Yeau-Ren Jeng ${ }^{\star}$ and Bernard J. Hamrock \\ National Aeronautics and Space Administration \\ Lewis Research Center \\ Cleveland; Ohio 44735 \\ David E. Brewe \\ Propulsion Directorate \\ U.S. Army Aviation Research and Technology Activity - AVSCOM \\ Lewis Research Center \\ Cleveland, Ohio 44135
}

\section{ABSTRACT}

The analysis in this paper is concerned with the piezoviscous-rigid regime of lubrication for the general case of elliptical contacts. In this regime several formulas of the lubricant film thickness have been proposed by Hamrock and Dowson; by Dowson et al., and more recently by Houpert. However, either they do not include the load parameter $W$, which has a strong effect on film thickness, or they overestimate the film thickness by using the Barus formula for pressure-viscosity characteristics. In the current study the Roelands formula has been used for the pressure-viscosity relationship. The effects of the dimensionless load, speed, and materials parameters, the radius ratio, and the lubricant entrainment direction have been investigated. The dimensionless load parameter was varied over a range of one order of magnitude. The dimensionless speed parameter was varled by 5.6 times the lowest value. Conditions corresponding to the use of solid materials of steel, bronze, and stlicon nitride and lubricants of paraffinic and naphthenic mineral oil were considered in obtaining the exponent in the dimensionless materials parameter: The radius ratio was varied from 0.2 to 64 (a configuration approaching a line contact). Forty-one cases were used in obtaining the minimum film thickness formula:

$$
H_{0}=178 G^{0.386} U^{1.266} W^{-0.880}\left(1-e^{-0.0387 \alpha}\right)
$$

\footnotetext{
*Case Western Reserve University, Cleveland, Ohio, and NASA Resident Research Associate. Work prepared under grant NCC3-30.
} 
Contour plots indicate in detail the pressure developed between the contacting solids.

\section{NOMENCLATURE}

D difference, $\left[\left(\tilde{H}_{0}-H_{0}\right) / H_{0}\right] \times 100$, percent

E modulus of elasticity, $\mathrm{N} / \mathrm{m}^{2}$

$E^{\prime} \quad$ effective elastic modulus, $2 /\left[\left(1-v_{A}^{2}\right) / E_{A}+\left(1-v_{B}^{2}\right) / E_{B}\right], N / m^{2}$

G dimensionless materials parameter, $E \% P_{i v, a s}$

H dimensionless film thickness, $h / R$

$H_{\text {min }}$ dimensionless minimum film thickness, $h_{\min } / R_{x}$

$H_{0} \quad$ dimensionless central film thickness, $h_{0} / R$

$\tilde{H}_{0} \quad$ calculated dimensionless central film thickness from least-squares analysis

h film thickness, m

$h_{\text {min }}$ minimum film thickness, $m$

$h_{0} \quad$ central film thickness (minimum film thickness as well in piezoviscous-rigid lubrication regime), m

P dimensionless pressure, $p / E^{\prime}$

p pressure, Pa

$p_{i v, a s}$ asymptotic isoviscous pressure, $\mathrm{N} / \mathrm{m}^{2}$

$R \quad$ effective radius, $m$

$r$ radius ratio

$s, t$ constants defining fluid, used in Eq. (8)

$U$ dimensionless speed parameter, $n_{0} U / E^{\prime} R_{x}$

$u \quad \sqrt{u_{x}^{2}+u_{y}^{2}}, \mathrm{~m} / \mathrm{s}$

$u_{x} \quad$ surface velocity in $x$ direction, $\mathrm{m} / \mathrm{s}$

$u_{y} \quad$ surface velocity in y direction, $\mathrm{m} / \mathrm{s}$

$W$ dimensionless load parameter, $W / E^{\prime} R_{x}^{2}$ 


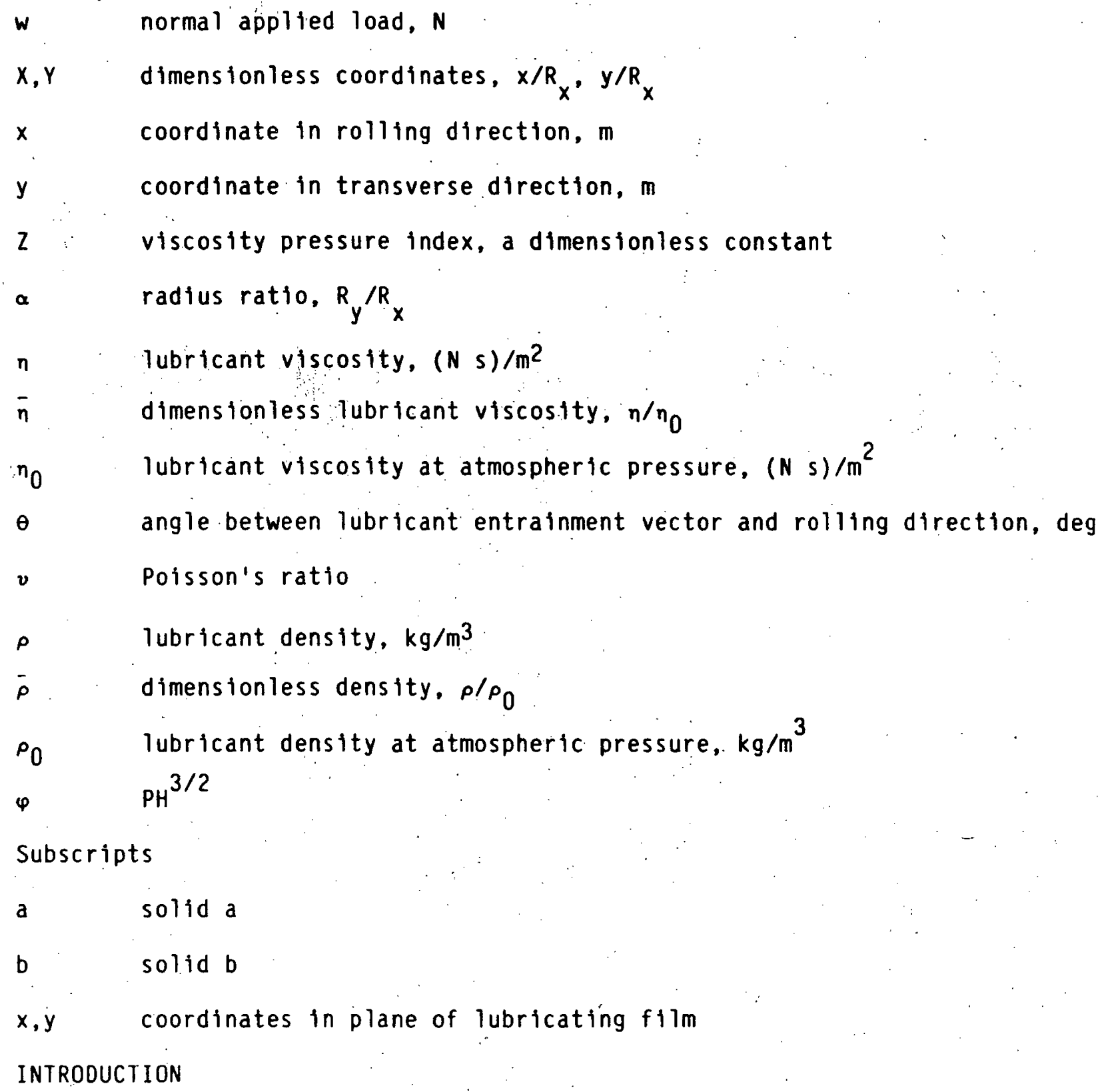

The development of fluid film lubrication, implying complete separation of the surfaces and no asperity contact, is influenced by two major physical effects: the elastic deformation of the solid under an applied load, and the variation of fluid viscosity with pressure. Therefore it is possible to have four main regimes of fluid flim lubrication (Hamrock and Dowson, 1981) depending on the magnitude of these effects and on their importance. The regimes can be described as (1) isoviscous-rigid, (2) piezoviscous-rigid, (3) isoviscous-elastic, and (4) piezoviscous-elastic. 
The hydrodynamic lubrication (isoviscous-rigid) theory was first applied to nonconformal contacts by Martin (1916). to explain the mechanism of gear lubrication. His solution of the Reynolds equation for the lubrication between two rigid circular cylinders by means of an isoviscous, incompressible fluid presented a useful beginning to theoretical studies. Nevertheless Martin's theoretical work discouraged the view that spur gears could be lubricated by hydrodynamic action since his results indicated that the film thickness. of spur gear lubrication was quite small compared with the surface roughness. A remarkable extension of the classical analytical solution for elliptical contacts lubricated by either an isoviscous or piezoviscous fluid was obtained by Kapitza (1955). However, applying the half-Sommerfeld boundary condition used in Kapitza's analysis violated flow continuity at the cavitation boundary. Brewe et a1. (1979) obtained a film thickness equation for the lubrication of fully flooded, rigid, isoviscous point contacts through a numerical analysis that used a more realistic Reynolds boundary condition for the film rupture in the exit region. He found that the minimum film thickness had the same speed, viscosity, and load dependence as in Kapitza's classical solution. However, the incorporation of the Reynolds boundary condition resulted in an additional geometry effect.

In the piezoviscous-rigid regime of lubrication the pressure within the contact is sufficiently high to increase the fluid viscosity significantly within the contact while the deformation of the surfaces remains an insignificant part of the fluid film thickness. This form of lubrication is encountered on roller end-guide flanges, in contacts in moderately loaded cylindrical tapered rollers, and between some piston rings and cylinder liners.

In the piezoviscous-rigid regime of lubrication Marko and Clegg (1979) proposed a formula obtained by means of curve fitting Dowson and Whitaker's (1965) results for line contacts. For point contacts Hamrock and Dowson 
(1978) proposed as an interim measure that Blok's (1952) solution for line contacts be adjusted by applying the same "side-leakage factor" as that derived for the piezoviscous-elastic condition. Dowson et al. (1983) obtained the numerical solution for a compressible Newtonian lubricant exhibiting pressure-viscosity characteristics and subject to the Reynolds cavitation boundary condition. The formulas from the last two papers describe the "limiting" film thickness generating infinite pressures, as discussed by Blok (1952). However, they do not include the load parameter $W$, which has a strong effect on film thickness when piezoviscous effects are considered. Houpert (1984) developed a sophisticated general formula by curve fitting Dalmaz's (1979) results. A shortcoming of Dalmaz's (1979) work is that he used the Barus exponential formula for pressure-viscosity characteristics. That formula tends to give higher values of viscosity than the results obtained from Roelands formula (Jones et al., 1975). Furthermore Dalmaz's (1979) results for the isoviscous case produced a lower exponent on w/U than did Brewe et al. (1979). This appears to be due to starvation effects entering the fully flooded results from the designation of the inlet boundary condition. Figure 1, obtained from Meuleman et al. (1985), shows the differences between the Barus formula, the Roelands formula, and the experimental data of Hirst and Moore (1979). It is apparent that the Roelands formula represents the experimental result for the pressure-viscosity relationship more accurately than the Barus formula at high pressures. Therefore the Roelands formula is used in this study. The researchers in the past used the Barus formula and neglected the lubricant compressibility to obtain straightforward numerical analysis of the resulting linear partial differential equation. The numerical analysis employed in this study is more complicated because the resulting partial differential equation is now nonlinear. 
In the current study the numerical solution for the piezoviscous-rigid lubrication regime is presented for the fuli spectrum of conditions. The influence of lubricant entrainment direction has also been studied. The condition that the lubricant entraining vector is not parallel to the minor axis of the contact might arise, for example, in helical, spiral bevel, and hypoid gears. The radius ratio was varied from 0.2 to 64 to cover any contact ranging from something similar to a disk rolling on a plate $(\alpha<1)$ to a contact approaching a nominal line contact $(\alpha \rightarrow 70)$ such as a barrel-shaped roller against a plate. The effects of the dimensionless speed, load, and materials parameters on minimum film thickness were also investigated. The dimensionless load parameter was varied over a range of an order of magnitude. The dimensionless speed parameter was varied over a range 5.6 times the lowest speed value. "Conditions corresponding to the use of solid materials of steel, bronze, and silicon nitride and lubricants of paraffinic and naphthenic mineral oils were considered in obtaining the exponent in the dimensionless materials parameter. Forty-one cases were used to obtain a simple empirical minimum film thickness formula. Contour plots are shown that indicate in detall the pressure developed between the solids.

METHOD OF CALCULATION

Reynolds Equation

For the coordinate systems $x, y$ the general Reynolds equation for point contact can be expressed as

$$
\frac{\partial}{\partial x}\left(\frac{\rho h^{3}}{12 \eta} \frac{\partial p}{\partial x}\right)+\frac{\partial}{\partial y}\left(\frac{\rho h^{3}}{12 \eta} \frac{\partial p}{\partial y}\right)=\frac{\partial}{\partial x}\left[\frac{\rho\left(u_{a x}+u_{b x}\right) h}{2}\right]+\frac{\partial}{\partial y}\left[\frac{\rho\left(u_{a y}+u_{b y}\right) h}{2}\right]
$$

where

$u_{a x}$ surface velocity of solid $a$ in $x$ direction
$u_{b x}$ surface velocity of solid $b$ in $x$ direction


$u_{\text {ay }}$ surface velocity of solid a in $y$ direction

uby surface velocity of solid b in $y$ direction

If the surface velocities are assumed to be constant, the Reynolds equation can be expressed as

$$
\frac{\partial}{\partial x}\left(\frac{\rho h^{3}}{12 \eta} \frac{\partial p}{\partial x}\right)+\frac{\partial}{\partial y}\left(\frac{\rho h^{3}}{12 \eta} \frac{\partial p}{\partial y}\right)=u_{x} \frac{\partial}{\partial x}(\rho h)+u_{y} \frac{\partial}{\partial y}(\rho h)
$$

where

$u_{x}=\left(u_{a x}+u_{b x}\right) / 2$

$u_{y}=\left(u_{a y}+u_{b y}\right) / 2$

By introducing $u$ and $\theta$, where $u=\sqrt{u_{x}^{2}+u_{y}^{2}}$ and $\theta=\tan ^{-1}\left(u_{x} / u_{y}\right)$

Eq. 2 becomes

$$
\frac{\partial}{\partial x}\left(\frac{\rho h^{3}}{\eta} \frac{\partial p}{\partial x}\right)+\frac{\partial}{\partial y}\left(\frac{\rho h^{3}}{\eta} \frac{\partial p}{\partial y}\right)=12 u\left[\cos \theta \frac{\partial(\rho h)}{\partial x}+\sin \theta \frac{\partial(\rho h)}{\partial y}\right]
$$

By letting

$$
X=\frac{x}{R_{X}}, \quad Y=\frac{y}{R_{y}}, \quad \bar{\rho}=\frac{e}{\rho_{0}}, \quad \bar{n}=\frac{\eta}{\eta_{0}}, \quad H=\frac{h}{R_{X}}, \quad P=\frac{p}{E^{\prime}}
$$

Eq. (3) can be described in the dimensionless form as

$$
\frac{\partial}{\partial X}\left(\frac{\bar{\rho} H^{3}}{\bar{n}} \frac{\partial P}{\partial X}\right)+\frac{\partial}{\partial Y}\left(\frac{\bar{\rho} H^{3}}{\bar{n}} \frac{\partial P}{\partial Y}\right)=12 u\left[\cos \theta \frac{\partial(\bar{\rho} H)}{\partial X}+\sin \theta \frac{\partial(\bar{\rho} H)}{\partial Y}\right]
$$

where

$$
u=n_{0} u / E^{\prime} R_{x}
$$

Equation (4) is the Reynolds equation for which the dimensionless pressure $P$ will be determined. However, before proceeding, the dimensionless density. $\rho_{0}$, the dimensionless viscosity $n_{0}$, and the dimensionless film thickness H will have to be expressed. 
Pressure-Viscosity Formula

It is generally known that the viscosity of a lubricant is a function of temperature and pressure. A generally accepted"relationship that describes the pressure-viscosity dependency is the Barus equation

$$
n=n_{0} e^{\alpha p}
$$

where

n viscosity at gauge pressure

$n_{0}$ viscosity at atmospheric pressure

a pressure-viscosity coefficient of lubricant

Unfortunately pressure-viscosity data seldom follow this simple relationship. and $1 t$ is valid as a reasonable approximation only in a moderate-pressure range.

Roelands (1966) in a more extensive experimental study of the effect of pressure on the viscosity of lubricants has developed an empirical formula written as

$$
\log n+1.200=\left(\log n_{0}+1.200\right)\left(1+\frac{p}{2000}\right)^{2}
$$

where

p gauge pressure, $\mathrm{kgf} / \mathrm{cm}^{2}$

2 viscosity index, a dimensionless constant

Rearranging terms gives

$$
n=n_{0}(1+p / 2000)^{2} \times 10^{7.2\left[(1+p / 2000)^{2}-1\right]}
$$

The temperature effect is normally accounted for in ${ }_{0}$. Pressure-Density Formula

The variation of density with pressure is roughly linear at low pressures, but the rate of increase falls away at high pressures. From Dowson and Higginson (1966) the dimensionless density for mineral oil can be written as 


$$
\bar{\rho}=\frac{e}{\rho_{0}}=i+\frac{s p}{1+t p}
$$

where $s$ and $t$ are constants that depend on the fluid.

Film Thickness

The separation of two rigid solids a and b having radif of curvature $r_{a x}, r_{a y}$ and $r_{b x}, r_{b y}$ in the vicinity of the point of closest approach can be considered as a geometrically equivalent solid of principal radii. $R_{x}, R_{y}$ adjacent to a plane, as shown in Fig. 2. The effective radius of curvature can be expressed as

$$
\begin{aligned}
& \frac{1}{R_{x}}=\frac{1}{r_{a x}}+\frac{1}{r_{b x}} \\
& \frac{1}{R_{y}}=\frac{1}{r_{a y}}+\frac{1}{r_{b y}}
\end{aligned}
$$

It is assumed that convex surfaces exhibit positive curvature, and concave surfaces negative curvature. Therefore, if the center of curvature lies within the solid, the radius of curvature is positive; if the center of curvature lies outside the solid, the radius is negative.

The film thickness between two rigid bodies in point contact can be written as

$$
h=h_{0}+s(x, y)
$$

The separation of two rigid solids (fig. 2(a)) in which the principal axes of inertia of the two bodies are parallel can be written as

$$
S=S_{a x}+S_{b x}+S_{a y}+S_{b y}
$$


where

$$
\left.\begin{array}{l}
s_{a x}=r_{a x}-\sqrt{r_{a x}^{2}-x^{2}} \\
s_{b x}=r_{b x}-\sqrt{r_{b x}^{2}-x^{2}} \\
s_{a y}=r_{a y}-\sqrt{r_{a y}^{2}-y^{2}} \\
s_{b y}=r_{b y}-\sqrt{r_{b y}^{2}-y^{2}}
\end{array}\right\}
$$

The separation in terms of the coordinates and the effective radius of curvature (Fig. $2(b)$ ) is

$$
S(x, y)=R_{x}-\sqrt{R_{x}^{2}-x^{2}}+R_{y}-\sqrt{R_{y}^{2}-y^{2}}
$$

Substituting Eq. (12) into Eq. (11) while at the same time making this equation dimensionless gives

$$
H=H_{0}+1-\sqrt{1-x^{2}}+\alpha\left[1-\sqrt{1-\left(\frac{Y}{\alpha}\right)^{2}}\right] .
$$

where $\dot{\alpha}=R_{y} / R_{x}$.

Boundary Conditions

There are two boundary conditions:

(1) The Reynolds boundary condition is applied in the divergent film. Name ly, $P=d P / d X=d P / d Y=0$ at the cavitation boundary.

(2) The pressure on the boundaries of the computation region is assumed to be zero. The fully flooded conjunction is considered in the present study (i.e.. increasing the computation region of the conjunction does not affect the results).

NUMERICAL ANALYSIS

Having defined the density, viscosity, and film thickness, we are in a position to solve the Reynolds equation subjected to the Reynolds cavitation boundary condition. The dimensioniess pressure $P$ is notorious for its steep gradient, which is not welcome when performing numerical analysis via 
relaxation methods. To produce a more gentle curve, a parameter $\varphi$ is introduced where

$$
\varphi=\mathrm{PH}^{3 / 2}
$$

This substitution also has the advantage of eliminating all terms containing derivatives of products of $H$ and $P$ or $H$ and $\varphi$. Substituting Eq. (14) into Eq. (4), we obtain

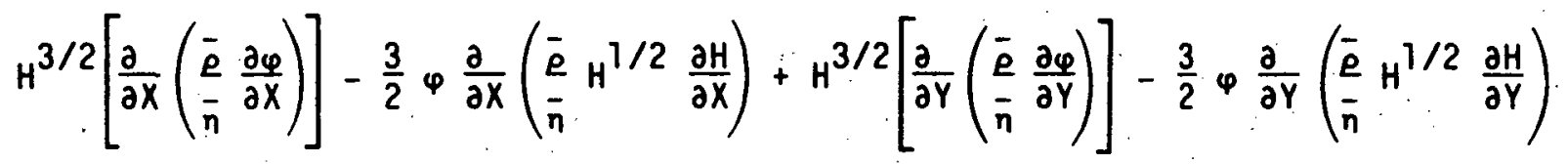

$$
\begin{aligned}
& =12\left[\cos \theta \frac{\partial(\bar{\rho} H)}{\partial X}+\sin \theta \frac{\partial(\bar{\rho} H)}{\partial Y}\right]
\end{aligned}
$$

The method of frozen coefficients (sometimes also referred to as Kacanov's method (Fučik et al. (1975)) is applied to solve this nonlinear partial differential equation. Second-order central finite difference approximations to the modified form of the Reynolds equation are used, thus forming a set of algebraic equations that are solved by the Gauss-Seidel iterative method with overrelaxation. For optimal efficiency a variable-mesh structure is used to enhance the accuracy in the region of high pressure and large pressure gradient.

The normal applied load can be evaluated by

$$
w=\int_{y_{0}}^{y_{m}} \int_{x_{0}}^{x_{n}} p(x, y) d x d y
$$

The double simpson's integration technique is applied to the integration. RESULTS

Dimensionless Grouping

From the variables of the numerical analysis the following dimensionless groupings are written:

(1) Dimensionless film thickness

$$
H=h / R_{X}
$$


(2) Dimension less load parameter:

$$
W=W / E^{\prime} R^{2}
$$

(3) Dimensionless speed parameter.

where $u^{\prime}=\sqrt{u_{x}^{2 w}+u_{y}^{2}}$.

$$
U^{\prime}=n_{0} U / E^{\prime} R_{x}
$$

(4) Dimensionless materials parameter

$$
G=E^{\prime} / P_{\text {iv, as }}
$$

where $p_{\text {ivas }}$ is the asymptotic, isoviscous pressure gradient obtained from Roelands (1.966)

(5) Radius ratio

$$
\alpha=R_{y} / R_{x}
$$

(6) Lubricant entraining angle

$$
\theta=\tan ^{-1}\left(u_{y} / u_{x}\right) \text { in degrees }
$$

The dimensionless film thickness can thus be written as a function of the other five parameters:

$$
H_{0}=f(W, U, \alpha, G, \theta)
$$

The most important practical aspects of hydrodynamic lubrication of nonconformal contacts is the determination of the minimum film thickness within the contact. Therefore in the fully flooded results to be presented the dimensionless parameters ( $W, U, \alpha, G$, and $\theta)$ will be varied, and the effect on the minimum film thickness will be studied. Note that in Eqs. (17) to (21), by changing the normal applied load $w$, the dimensionless load $w$ is changed, but the other dimensionless parameters remain unchanged. Similar statements can be made about changing $u_{x}$ in the dimensionless speed $U$ and $R_{x}$ in the radius ratio.

Influence of Load

The dimensionless parameters $U, G, \alpha$, and $\theta$ were kept constant while varying the dimensionless minimum film thickness $H_{0}$ to get the dimensionless 
load capacity $W$ at each different $H_{0}$. The values at which the remaining parameters $U, G, \alpha$, and $\theta$ were held constant during the calculations were $U=0.16833 \times 10^{-11}, G=4522, \alpha=16$, and $\theta=0$.

Table 1 shows the computed load capacities for 10 values of minimum film thickness. From these 10 pairs of data it is possible to determine a good empirical relationship between the minimum film thickness $H_{0}$ and the load capacity $W:$

$$
H_{0}=C_{1} W^{C_{2}}
$$

By applying a least-squares power fit to the 10 pairs of data $\left[\left(W_{\mathfrak{q}}\right.\right.$, $\left.\left.H_{0, i}\right), i=1,2, \ldots, 10\right]$, the values of $C_{1}$ and $C_{2}$ were found to be $c_{1}=2.60615 \times 10^{-12} \approx 2.606 \times 10^{-12}$ and $c_{2}=-0.88019 \approx-0.880$. From the value of $C_{2}$ and Eq. (24) the effect of load on minimum film thickness is written as

$$
\tilde{H}_{0} \propto W^{-0.880}
$$

In Fig. 3 the variation of dimensionless minimum film thickness with dimensionless load is plotted for 10 data points. On a log-log scale the plot is linear. The percentage difference between the minimum film thickness obtained from computational results $H_{0}$ and the minimum film thickness obtained from the least-squares fit equation $\tilde{H}_{0}$ is expressed as

$$
D=\left[\left(\tilde{H}_{0}-H_{0}\right) / H_{0}\right] \times 100
$$

Influence of Speed

If the surface velocity $u$ is changed, the dimensionless speed parameter $U$ is modified as shown in Eq. (19), but the other dimensionless parameters $\left(H_{0}, G, \alpha\right.$, and $\left.\theta\right)$ remain constant. The values at which these dimensionless parameters were held constant in the calculations performed to determine the influence of speed on film thickness are

$$
\alpha=16, H_{0}=4.8 \times 10^{-6}, G=4522, \theta=0
$$


Values of the dimensionless speed parameter $U$ and the corresponding dimensionless load capacities as obtained from the numerical computations are presented in Table 2. Since the relationship between the minimum film thickness $H_{0}$ and the load capacity $W$ has been obtained, the relationship between the minimum film thickness and the speed parameter can be written in the form

$$
H_{0} / W^{-0.880}=C_{3} U^{C_{4}}
$$

By applying a least-squares fit to the six pairs of data $\left[U_{f}, H_{0,1}\right)$, $i=1, \ldots, 6]$, the values of $c_{3}$ and $c_{4}$ were found to be $c_{3}=1.4899 \times 10^{-13} \approx 1.49 \times 10^{-13}$ and $C_{4}=1.2655 \approx 1.266$. From the value obtained for $C_{4}$ and $E q$. (27) the effect of dimensionless speed on dimensionless film thickness can be written an

$$
H_{0} \propto U^{1.266}
$$

The data presented in Table 2 are plotted in Fig. 4. As was true for the load-versus-film-thickness results, the speed-versus-film-thickness results are linear when plotted on a log-log scale.

Influence of Radius Ratio

To study the effect of geometry on minimum film thickness, the dimensionless parameters for minimum film thickness $H_{0}$, speed $U$, materials G, and lubricant entrainment direction $\theta$ were held constant at the following values:

$$
H_{0}=4.8 \times 10^{-6}, U=0.1683 \times 10^{-11}, G=4522, \theta=0
$$

Table 3 shows the computed values of dimensionless load capacity for 22 values of radius ratio. It is possible to determine a good empirical relationship between $H_{0}$ and $\alpha$ for the condition considered in the computation. The form of relationship chosen after investigating a number of different expressions can be written as 


$$
1-\left(H_{0} / H_{0}, r\right)=\tilde{A} e^{\tilde{B}}
$$

where $H_{0, r}$ is chosen to be the film thickness at rectangular contact.

A least-squares exponential curve was fitted to the 22 pairs of data points to obtain values for $\tilde{A}$ and $\tilde{B}$ in Eq. $(29): \tilde{A}=0.989 \approx 1.00$ and $\widetilde{B}=0.03866 \approx 0.0387$. Substituting these values into Eq. (29) resulted in the following relationship between the radius ratio and minimum film thickness:

$$
H_{0} \propto\left(1-e^{-0.0387 \alpha}\right)
$$

The effect of radius ratio on film thickness for the 22 data points is shown in Fig. 5. It is most significant that the computed value of $\tilde{A}$ is approximately unity since this ensures that the minimum film thickness approaches zero as the radius ratio goes to zero. Contour plots for three radius ratios (i.e., a of 16,8 , and 4) are shown in Fig. 6 to demonstrate the influence of geometry. Since the isobars in each case are evenly spaced, the pressure gradients can be easily depicted. As the radius ratio increases, the steeper pressure gradients are predominantiy along the rolling direction. This implies that the amount of side leakage decreases as radius ratio increases. Figure 7 shows that the geometry effects in four regimes of lubrication (1.e., hard EHL (Hamrock and Dowson, 1977), soft EHL (Hamrock and Dowson, 1978), piezoviscous-rigid, and isoviscous-rigid (Brewe et al., 1979)), where $H_{\min , r}$ is the minimum film thickness for rectangular contacts. It is assumed that when $\alpha=150$, the rectangular contact limit is realized. The ratio $H_{\min } / H_{\min , r}$ approaches the limiting value very quickly in hard EHL, and most slowly in the isoviscous-rigid case.

Influence of Material Properties

A study of the influence of the dimensionless materials parameter $G$ on minimum film thickness has to be approached with caution since in practice it is not possible to change the physical properties of the materials, and hence 
the value of $G$, without influencing the other dimensionless parameters considered earlier. Equations (18) to (20) show that when either the materials of the solids (as expressed in $E^{\prime}$ ) or the other lubricants (as expressed in $n_{0}$ and. $P_{\text {iv,as }}$ ) are varied, not only does $G$ change, but so do the dimensionless speed $U$ and load $W$ parameters. Only the radius ratio, minimum film thickness, and lubricant entrainment direction can be held fixed; and for all results presented in Table $4, H_{0}=4.8 \times 10^{-6}$ or $1.4 \times 10^{-6}, \alpha=16$, and $\theta=0$ are adopted.

The results obtained from calculations performed for six values of the dimensionless materials parameter are summarized in Table 4 . The general form of these results, showing how the minimum film thickness is a function, of the dimensionless materials parameter, is

$$
\tilde{C}=C_{7}{ }^{C_{8}}
$$

where

$$
\tilde{C}=H_{0} /\left[\left(1-e^{-0.0387 \alpha}\right) u^{1.266} W^{-0.880}\right]
$$

By applying a least-squares power fit to the six pairs of data, the values of $c_{7}$ and $c_{8}$ were found to be $c_{7}=175.04$ and $c_{8}=0.386096 \approx 0.386$.

The effect of the dimensionless materials parameter on the minimum film. thickness is approximated with adequate accuracy as

$$
H_{0} \propto G^{0.386}
$$

The variation of dimensionless materials parameter $G$ with dimensionless film thickness $H_{0}$ is shown in Fig. 8. The six data points given in Table 4 are shown in this figure. Again, on the log-log scale the representation of the materials parameter versus film thickness is linear. Influence of Lubricant Entrainment Direction

If the velocity. of the entrainment lubricant is kept constant but the component velocity in the $x$ direction $u_{x}$ and the component velocity in the 
$y$ direction $u_{y}$ are changed, the lubricant entraining angle is modified as shown in Eq. (22) while the other dimensionless parameters $\left(H_{0}, G\right.$, and $\left.a\right)$ remain constant. The values at which these dimensionless parameters are held constant in the calculations performed to determine the effect of lubricant entrainment direction are

$$
\alpha=20, H_{0}=5.6 \times 10^{-6}, G=4522, U=0.75749 \times 10^{-11}
$$

The results obtained from calculations performed for 10 values of the lubrication entrainment direction are summarized in Table 5. A cosine function was chosen for curve fitting, namely

$$
\widetilde{T}=C_{9} \theta
$$

where $\tilde{T}=\cos ^{-1}\left(W^{-0.880} / W_{0}^{-0.880}\right)$ and $W_{0}$ denotes the load capacity at $\theta=0$. By applying a least-squares fit to the 10 pairs of data, the value of $C_{9}$ was found to be $C_{9}=0.0200027 \approx 0.0200$. Therefore the effect of the lubricant entrainment direction on the minimum film thickness can be written as

$$
H_{0} \propto \cos (1.146 \theta)
$$

This is shown in Fig. 9. It is significant that when the entraining angle is zero, the cosine function turns out to be 1 . In other words, there is no effect of lubricant entrainment direction on minimum film thickness. Although the influence of lubricant entrainment direction was investigated for $\theta=20^{\circ}$ only, it can be applied to the cases from $\theta=16^{\circ}$ to $\theta=30^{\circ}$. Minimum Film Thickness Formula

The proportionality Eqs. (25), (28), (30), and (34) have established how the minimum film thickness varied with the dimensionless load, speed, and materials parameters and radius ratio, respectively. This enables a composite dimensionless minimum film thickness formula for a fully flooded, rigid, elliptic-contact solid lubricated by a piezoviscous fluid to be modeled by 


$$
H_{0}=178 G^{0.386} U^{1.266} W^{-0.880}\left(1-e^{-0.0387 \alpha}\right)
$$

with 85.6 percent confidence (except for the small value of a) \pm 8.92 percent of the value from the numerical analysis. Equation (35) can be written in dimensional form as

$$
n_{0}-178\left(1 / p_{i v, a s}\right)^{0.386}\left(u_{n_{0}}\right)^{1.266_{W}-0.880_{R} 1.494}\left(1-e^{-0.0387 R_{y} / R_{x}}\right)
$$

Note that the effective elastic modulus $E^{\prime}$ does not appear in this equation. Cases 1 to 41 in Table 6 were used in obtaining Eq. (35). To gain more confidence in the application of this empirical equation, some other values of dimensionless speed $U$ and minimum film thickness $H_{0}$ not in the range for curve fitting were checked. The results are shown in cases 52 and 53 of Table 6. The good agreement between the prediction from the minimum film thickness formula and computed results is encouraging.

DISCUSSION

A numerical solution for the piezoviscous effect in nonconformal rigid contacts lubricated hydrodynamically has been developed. The following remarks can be made:

(1) The effective elastic modulus $E^{\prime}$ does not appear in the dimensional film thickness equation. This corresponds to a rigid contact; there is no effect of elastic properties.

(2) In all cases, if the maximum dimensionless viscosity was less than 3 , the load capacity was no more than 12 percent larger than the load capacity without the piezoviscous effect. This indicates a very small piezoviscous effect. All the data sets used to generate Eq. (35) had maximum dimensionless viscosity larger than 3 . 
(3) The exponents of dimensionless load and dimensionless speed in the minimum film thickness equation for the piezoviscous-rigid regime were between those for the plezoviscous-elastic regime and the isoviscous-rigid regime.

(4) The film thickness formula according to the side-leakage factor proposed by Hamrock and Dows on (1978) is

$$
H_{0}=1.66(G U)^{2 / 3}\left\{1-\exp \left[-0.68\left(1.03 \alpha^{0.66}\right)\right]\right\}
$$

The more recent formula from the numerical solution by Dowson et al. (1983) is .

$$
H_{0}=1.66(G U)^{2 / 3}\left(\frac{\alpha}{1+\alpha}\right)^{0.6}
$$

Figure 10 compares the minimum film thickness as obtained from Eqs. (37) and (38) with the present result for $W=0.6 \times 10^{-7}$ or $0.9 \times 10^{-7}$ and $\alpha=8$ or 16 . The deviations are large for small values of GU. The deviations resulted because the load parameter $W$ was not included in Eqs. (28) and (29), giving erroneous results when the plezoviscous effects are small (i.e., GU. is small), and because the Barus formula was used for the pressure-viscosity correlation in Eqs. (37) and (38) and caused an overestimate of the minimum film thickness.

(5) The film thickness formula proposed by Houpert (1984) by means: of curve fitting the numerical solution of Dalmaz is

$$
\begin{aligned}
& \mathrm{H}_{\mathrm{pvr}}=\mathrm{CH}_{\text {ivr }} \\
& C=\exp (0.265 \mathrm{~A}) \\
& \begin{array}{l}
H_{i v r}=\left\{\frac{\left(1+\frac{2}{3 \alpha}\right) \frac{W}{U}}{\left[0.131 \tan ^{-1}\left(\frac{\alpha}{2}\right)+1.683\right] \sqrt{128 \alpha}}+2.6511\right\} \\
A=12 \mathrm{GU} \frac{0.177 \alpha}{\alpha+0.778} H_{i v r}^{-1.5}
\end{array}
\end{aligned}
$$

Twenty of the 41 cases used to get the present formula (Eq. (35)) were compared with the formula proposed by Houpert. Table 7 shows the ratio of $H_{0}$ (Eq. (39)) to $\mathrm{H}_{0}$ (Eq. (35)). The deviation is between 28 and 54 percent. 
A possible cause of this difference may be that Houpert's (1984) results imply an incompressible flutd and the Barus pressure-viscosity formula. SUMMARY OF RESULTS

A procedure for the numerical solution of the complete piezoviscous-rigid regime of lubrication for nonconformal contacts has been demonstrated. In the numerical analysis of the Reynolds equation, the parameter $\varphi=\mathrm{PH}^{3 / 2}$ was introduced to help the relaxation process. A varlable-mesh nodal structure was used to provide close spacing in and around the pressure peak. A more realistic formula is used for the pressure-viscosity relationship. Lubricant compressibility was also considered.

By using the procedures outlined in the analysis, the effects of the dimensionless load $W$, speed $U$, and materials $G$ parameters, radius ratio $a$, and lubricant entraining direction $\theta$ on minimum film thickness were investigated. Forty-one cases were used to generate the minimum film thickness relationship

$$
H_{0}=178 G^{0.386} U^{1.266} W^{-0.880}\left(1-e^{-0.0387 \alpha}\right)
$$

The most dominant exponent occurs in association with the speed parameter; the exponent on the load parameter -0.880 is between -2 for the isoviscous-rigid regime and -0.073 for the piezoviscous-elastic regime. The materials parameter also carries a significant exponent, although the range of the parameter in engineering is limited. The geometry effect shows the same curve as in elastohydrodynamic lubrication but approaches the limiting value much more slowly. The effect of the direction of lubricant entrainment is a cosine function for the geometries studied. The dimensionless load parameter values used in obtaining the preceding equation were varied over a range of one order of magnitude. The dimensionless speed values were varied by 5.6 times the lowest value. Conditions corresponding to the use of solid 
materials of steel, bronze, and silicon nitride and lubricants of paraffinic and naphthenic mineral ofls are considered in obtaining the exponent in. the dimensionless materials parameter. The radius ratio was varied from 0.2 to 64 (a configuration approaching a line contact). Contour plots are shown that indicate in detail the pressure developed between the solids.

\section{REFERENCES}

Blok, H., "Discussion of Paper by E. McEwen," J. Inst. Petrol., 38, 673-683, (1952).

Brewe, D.E., Hamrock, B.J., and Taylor, C.M., "Effect of Geometry on Hydrodynamic Film Thickness," J. Lubr. Technol., 101, 237-239, (1979).

Dalmaz, G., "Le film mince visqueux dans les contacts hertziens en regimes hydrodynamique et elastohydrodynamique," Docteur d'Etat Es Sciences Thesis, I.N.S.A. Lyon, (1979).

Dowson, D. and Higginson, G.R., Elastohydrodynamic Lubrication, Pergamon Press, (1966).

Dowson, D. and Whitaker, A.V., "The Isothermal Lubrication of Cylinders," ASLE. Trans., 8, 224-234, (1965).

Dowson, D., Dunn, J.F., and Taylor, C.M., "The Piezo-viscous Fluid, Rigid Solid Regime of Lubrication," Proc. Inst. Mech. Eng., 197c, 43-52, (1983). Fučik, S., Kratochvíl, A., and Nečas, J., "Kačanov's Method and Its Application," Rev. Roum. Math. Pures Appl., 20, 907-916, (1975). Hamrock, B.J. and Dowson, D., "Isothermal Elastohydrodynamic Lubrication of Point Contacts, Part III - Fully Flooded Results," J. Lubr. Technol., 99, $264-276,(1977)$

Hamrock, B.J. and Dowson, D., "Elastohydrodynamic Lubrication of Elliptical Contacts for Materials of Low Elastic Modulus, Part I - Fully Flooded Conjunction," J.Lubr. Technol., 100, 236-245, (1978). 
Hamrock, B.J. and Dowson; D., Ball Bearing Lubrication - The

Elastohydrodynamics of Elliptical Contacts, John Wiley \& Sons, New York, (1981).

Hirst, W. and Moore, A.J., "E.lastohydrodynamic Lubrication at High

Pressure, Part 2 - Non-Newtonian Behavior," Proc. R. Soc., London, A., 365, 537-565, (1979) .

Houpert, L., "The film Thickness in Piezoviscous-Rigid.Regime; Film Thickness Lubrication Regimes Transition Criteria," J. Lubr. Technol., 106, 375-385, (1984).

Jones., W.R., Jr., Johnson, R.L., Wther, W.O., and Sanborn, D.M., "Pressure-Viscosity Measurements for Several Lubricants to $5.5 \times 10^{8}$ Newtons per Square Meter $\left(8 \times 10^{4}\right.$ psi) and $149^{\circ} \mathrm{C}\left(300^{\circ} \mathrm{F}\right)$, ASLE Trans., 18. $249-262,(1975)$.

Kapitza, P.L., "Hydrodynamic Theory of Lubrication during Rolling," Zh. Tekh. Fiz., 25, 747-762, (1955).

Màrkho, P.H., and Clegg, D.B., "Reflections on Some Aspects of Lubrication of Concentrated Line Contacts," J. Lubr. Technol., 101, 528-531, (1979). Martin, H.M.,. "The Lubrication of Gear Teeth," Engineering (London), 102. $119-121,(1916)$.

Meuleman, P.K., Lubrecht, A.A., and Nape1, W.E., "Traction in Elastohydrodynamic Lubrication - High Contact Pressure Experiments and a Therma 1 Roelands-Eyring-Maxwe 11 Mode1, "Department of Mechanical Engineering, Twente University of Technology, Enschede, The Netherlands (1985). Roelands, C.J.A., Correlational Aspect of the Viscosity-Temperature-Pressure Relationship of Lubricating 0115 ," Druk V.R.B., Griningeon, Netherlands, (1966). 
TABLE 1 - EFFECT OF DIMENSIONLESS LOAD PARAMETER ON MINIMUM FILM THICKNESS

\begin{tabular}{|c|c|c|c|}
\hline $\begin{array}{c}\text { Dimensionless } \\
\text { load parameter }\end{array}$ W & \multicolumn{2}{|c|}{ Minimum film thickness } & $\begin{array}{c}\text { Difference, } \\
\text { D, } \\
\text { percent }\end{array}$ \\
\cline { 2 - 4 } & $\begin{array}{c}\text { Obtained from } \\
\text { computational } \\
\text { result, } \\
H_{0}\end{array}$ & $\begin{array}{c}\text { obtained from } \\
\text { least-squares } \\
\text { fjt, }\end{array}$ & \\
$\tilde{H}_{0}$ & \\
\hline $0.90971 \times 10^{-7}$ & $4.1 \times 10^{-6}$ & $4.13 \times 10^{-6}$ & 0.77 \\
.89091 & 4.2 & 4.21 & .20 \\
.85159 & 4.4 & 4.38 & -.48 \\
.80860 & 4.6 & 4.78 & -.37 \\
.77370 & 4.8 & 4.76 & -.75 \\
.74467 & 5.0 & 4.93 & -1.45 \\
.68766 & 5.2 & 5.29 & 1.64 \\
.65859 & 5.5 & 5.49 & -.18 \\
.64956 & 5.6 & 5.56 & -.77 \\
.63293 & 5.8 & 5.69 & -1.98 \\
\hline
\end{tabular}

TABLE 2 - EFFECT OF DIMENSIONLESS SPEED PARAMETER ON MINIMUM FILM THICKNESS

\begin{tabular}{|c|c|c|c|c|}
\hline \multirow{2}{*}{$\begin{array}{c}\text { Dimensionless } \\
\text { speed parameter, } \\
U\end{array}$} & \multirow{2}{*}{$\begin{array}{c}\text { Dimensionless } \\
\text { load parameter, } \\
W\end{array}$} & \multicolumn{2}{|c|}{ Minimum film thickness } & \multirow{2}{*}{$\begin{array}{c}\text { Difference, } \\
0, \\
\text { percent }\end{array}$} \\
\hline & & $\begin{array}{c}\text { Obtained from } \\
\text { computational } \\
\text { result, } \\
H_{0}\end{array}$ & $\begin{array}{c}\text { Obtained from } \\
\text { least-squares } \\
\text { f } j t, \\
\bar{H}_{0}\end{array}$ & \\
\hline $\begin{array}{l}0.21883 \times 10^{-11} \\
.20120 \\
.18516 \\
.16833 \\
.15150 \\
.13466\end{array}$ & $\begin{array}{l}1.17505 \times 10^{-7} \\
1.10085 \\
.88950 \\
.77377 \\
.67629 \\
.58454 \\
\end{array}$ & 4.8 & $\begin{array}{l}4.68 \\
.4 .83 \\
4.84 \\
4.85 \\
4.77 \\
4.68 \\
\end{array}$ & $\begin{array}{r}-2.56 \\
. .72 \\
.76 \\
.96 \\
-.53 \\
-2.58\end{array}$ \\
\hline
\end{tabular}


TABLE 3 - EFFECT OF ELLIPTICITY PARAMETER ON MINIMUM FILM THICKNESS

\begin{tabular}{|c|c|c|c|c|}
\hline \multirow{2}{*}{$\begin{array}{l}\text { Radius } \\
\text { ratio, } \\
a\end{array}$} & \multirow{2}{*}{$\begin{array}{c}\text { Dimension less } \\
\text { load parameter, } \\
W\end{array}$} & \multicolumn{2}{|c|}{ Minimum film thickness } & \multirow{2}{*}{$\begin{array}{c}\text { Difference, } \\
D, \\
\text { percent }\end{array}$} \\
\hline & & $\begin{array}{c}\text { Obtained from } \\
\text { computational } \\
\text { result, } \\
\mathrm{H}_{0}\end{array}$ & $\begin{array}{c}\text { Obtained from } \\
\text { least-squares } \\
\text { fit, } \\
\tilde{H}_{0}\end{array}$ & \\
\hline $\begin{array}{l}64 \\
61 \\
59 \\
58 \\
54 \\
49 \\
42 \\
34 \\
30 \\
27 \\
20 \\
18 \\
16 \\
12 \\
10 \\
8 \\
4 \\
1 \\
.8 \\
.6 \\
.4 \\
.2\end{array}$ & $\begin{array}{l}1.61064 \times 10^{-7} \\
1.59341 \\
1.56632 \\
1.55278 \\
1.49756 \\
1.42381 \\
1.13262 \\
1.17520 \\
1.09985 \\
1.04072 \\
.88157 \\
.83509 \\
.77377 \\
.60153 \\
.53541 \\
.45598 \\
.28576 \\
.12031 \\
.09028 \\
.09548 \\
.05424 \\
.02073\end{array}$ & $\begin{array}{l}\downarrow \\
3.0 \\
3.0 \\
2.0 \\
2.0 \\
1.5\end{array}$ & $\begin{array}{l}4.805 \times 10^{-6} \\
4.804 \\
4.828 \\
4.842 \\
4.900 \\
4.969 \\
5.044 \\
5.065 \\
5.039 \\
4.994 \\
4.669 \\
4.691 \\
4.616 \\
4.636 \\
4.764 \\
4.236 \\
3.445 \\
1.953 \\
2.019 \\
1.447 \\
1.593 \\
1.874\end{array}$ & $\begin{array}{r}0.10 \\
.09 \\
.58 \\
.89 \\
2.09 \\
3.52 \\
5.09 \\
5.52 \\
4.99 \\
4.04 \\
-2.83 \\
-2.27 \\
-3.84 \\
-3.42 \\
-7.57 \\
-11.66 \\
-28.22 \\
-34.91 \\
-32.70 \\
-27.65 \\
-20.36 \\
24.23\end{array}$ \\
\hline
\end{tabular}

TABLE 4 - EFFECT OF DIMENSIONLESS MATERIALS PARAMETER ON MINIMUM FILM THICKNESS

\begin{tabular}{|c|c|c|c|c|c|c|c|}
\hline \multirow{2}{*}{$\begin{array}{c}\text { Solid } \\
\text { material }\end{array}$} & \multirow[t]{2}{*}{ Lubricant } & \multicolumn{3}{|c|}{ Dimensionless parameter } & \multicolumn{2}{|c|}{ Minimum film thickness } & \multirow{2}{*}{$\begin{array}{c}\text { Difference, } \\
\text { D, } \\
\text { percent }\end{array}$} \\
\hline & & $\underset{G}{\text { Materials, }}$ & $\begin{array}{l}\text { Speed, } \\
U\end{array}$ & $\begin{array}{l}\text { Load, } \\
\text { W }\end{array}$ & $\begin{array}{c}\text { Obtained from } \\
\text { computational } \\
\text { result, } \\
\mathrm{H}_{0}\end{array}$ & $\begin{array}{c}\text { Obtained from } \\
\text { least-squares } \\
\text { fitt, } \\
\mathrm{H}_{0}\end{array}$ & \\
\hline $\begin{array}{l}\text { Steel } \\
\text { Bronze } \\
\text { Silicon } \\
\text { nitride }\end{array}$ & $\begin{array}{l}\text { Paraffinic } \\
\text { Paraffinic } \\
\text { Paraffinic }\end{array}$ & $\begin{array}{ll}4 & 522 \\
2 & 310 \\
6 & 785\end{array}$ & $\begin{array}{l}0.16832 \times 10^{-11} \\
.32957 \\
.11218\end{array}$ & $\begin{array}{l}0.77376 \times 10^{-7} \\
1.51499 \\
.51571\end{array}$ & $\begin{array}{l}4.8 \times 10^{-6} \\
4.8 \\
4.8\end{array}$ & $\begin{array}{l}4.68 \times 10^{-6} \\
4.682 \\
4.682\end{array}$ & $\begin{array}{l}-2.48 \\
-2.45 \\
-2.45\end{array}$ \\
\hline $\begin{array}{l}\text { Steel } \\
\text { Bronze } \\
\text { Silicon } \\
\text { nitride }\end{array}$ & $\begin{array}{l}\text { Naphthenic } \\
\text { Naphthenic } \\
\text { Naphthenic }\end{array}$ & $\begin{array}{rr}7 & 031 \\
3 & 591 \\
10 & 549\end{array}$ & $\begin{array}{l}.48123 \\
.94227 \\
.32073\end{array}$ & $\begin{array}{r}1.18602 \\
2.32216 \\
.79047\end{array}$ & $\begin{array}{l}1.4 \times 10^{-5} \\
1.4 \\
1.4\end{array}$ & $\begin{array}{l}1.441 \\
1.441 \\
1.441\end{array}$ & $\begin{array}{l}2.92 \\
2.92 \\
2.92\end{array}$ \\
\hline
\end{tabular}


TABLE 5 - EFFECT OF LUBRICANT ENTRAINMENT DIRECTION ON MINIMUM FILM THICKNESS

\begin{tabular}{|c|c|c|c|c|}
\hline \multirow{2}{*}{$\begin{array}{c}\text { Lubricant } \\
\text { entrainment } \\
\text { direction, } \\
\theta, \\
\text { deg }\end{array}$} & \multirow{2}{*}{$\begin{array}{l}\text { Dimensionless } \\
\text { load parameter, } \\
\quad W\end{array}$} & \multicolumn{2}{|c|}{ Minịmum film trickness } & \multirow{2}{*}{$\begin{array}{c}\text { Difference, } \\
D, \\
\text { percent }\end{array}$} \\
\hline & & $\begin{array}{c}\text { Obtained from } \\
\text { computational } \\
\text { result, } \\
\mathrm{H}_{0}\end{array}$ & $\begin{array}{c}\text { Obtained from } \\
\text { least-squares } \\
\text { fjt, } \\
\vec{H}_{0}\end{array}$ & \\
\hline $\begin{array}{l}0 \\
5 \\
10 \\
15 \\
20 \\
25 \\
30 \\
35 \\
40 \\
45\end{array}$ & $\begin{array}{l}0.14965 \times 10^{-6} \\
.14841 \\
.14532 \\
.14043 \\
.13427 \\
.12708 \\
.11941 \\
.11902 \\
.10200 \\
.09278\end{array}$ & $5.6 \times 10^{-6}$ & $\begin{array}{l}5.60 \times 10^{-6} \\
5.56 \\
5.54 \\
5.52 \\
5.50 \\
5.50 \\
5.54 \\
5.60 \\
5.49 \\
5.33\end{array}$ & $\begin{array}{l}0 \\
-.69 \\
-1.03 \\
-1.49 \\
-1.80 \\
-1.80 \\
-1.14 \\
0 \\
-1.94 \\
-4.88\end{array}$ \\
\hline
\end{tabular}


TABLE 6 - DATA SHOWING EFFECT OF LOAO, SPEED, RADIUS RATIO, MATERIALS PARAMETER, AND LUBRICANT ENTRAINMENT DIRECTION ON MINIMUM FILM THICKNESS

\begin{tabular}{|c|c|c|c|c|c|c|c|c|c|}
\hline \multirow[t]{2}{*}{ Case } & \multirow{2}{*}{$\begin{array}{c}\text { Dimensionless } \\
\text { load } \\
\text { parameter, } \\
\text { W }\end{array}$} & \multirow{2}{*}{$\begin{array}{c}\text { Dimension less } \\
\text { speed } \\
\text { parameter } \\
U\end{array}$} & \multirow{2}{*}{$\begin{array}{l}\text { Radius } \\
\text { ratio, } \\
\alpha\end{array}$} & \multirow{2}{*}{$\begin{array}{c}\text { Dimensionless } \\
\text { materials } \\
\text { parameter, } \\
\text { G }\end{array}$} & \multirow{2}{*}{$\begin{array}{c}\text { Lubricant } \\
\text { entrainment } \\
\text { direction, } \\
\theta, \\
\text { deg }\end{array}$} & \multicolumn{2}{|c|}{ Minimum film thickness } & \multirow{2}{*}{$\begin{array}{c}\text { Difference, } \\
D \\
\text { percent }\end{array}$} & \multirow[t]{2}{*}{ Results } \\
\hline & & & & & & $\begin{array}{c}\text { Obtained from } \\
\text { computational } \\
\text { results, } \\
H_{0}\end{array}$ & $\begin{array}{c}\text { Obtained from } \\
\text { least-squares } \\
\text { fit, } \\
\mathrm{H}_{0}\end{array}$ & & \\
\hline $\begin{array}{l}1 \\
2 \\
3 \\
4 \\
5 \\
6 \\
7 \\
8 \\
9 \\
10 \\
11 \\
12 \\
13 \\
14 \\
15 \\
16 \\
17 \\
18 \\
19 \\
20 \\
21 \\
22 \\
23 \\
24 \\
25 \\
20 \\
27 \\
28 \\
29 \\
30 \\
31 \\
32 \\
33 \\
34 \\
35 \\
30 \\
37 \\
38 \\
39 \\
40 \\
41 \\
42 \\
43 \\
44 \\
45 \\
46 \\
47 \\
48 \\
49 \\
50 \\
51 \\
52 \\
53\end{array}$ & $\begin{array}{l}0.90971 \times 10^{-7} \\
.89091 \\
.85159 \\
.80860 \\
.77376 \\
.74467 \\
.68766 \\
.65859 \\
.64956 \\
.63293 \\
1.17505 \\
1.00851 \\
.88950 \\
.67629 \\
.58454 \\
1.51499 \\
.51571 \\
1.18602 \\
2.32216 \\
.79047 \\
1.61064 \\
1.59341 \\
1.56632 \\
1.55278 \\
1.49756 \\
1.42381 \\
1.13262 \\
1.17520 \\
1.09985 \\
1.04072 \\
.88157 \\
.83509 \\
.60153 \\
.53541 \\
.45598 \\
.28570 \\
.12031 \\
.09028 \\
.09548 \\
.05424 \\
.02073 \\
1.49645 \\
1.48407 \\
1.45318 \\
1.40431 \\
1.34265 \\
1.27083 \\
1.19408 \\
1.10916 \\
1.02002 \\
.92775 \\
.10874 \\
.14001 \\
\end{array}$ & $\begin{array}{l}\mid \\
.21883 \\
.20120 \\
.18516 \\
.15150 \\
.13466 \\
.32957 \\
.11218 \\
.48123 \\
.94227 \\
.32073 \\
.16833 \\
1\end{array}$ & $\begin{array}{r}1 \\
64 \\
61 \\
59 \\
58 \\
54 \\
49 \\
42 \\
34 \\
30 \\
27 \\
20 \\
28 \\
12 \\
10 \\
8 \\
4 \\
1 \\
.8 \\
.6 \\
.4 \\
.2 \\
20 \\
1\end{array}$ & \begin{tabular}{rl|l} 
& \\
1 & & \\
2 & 310 \\
1 & 785 \\
7 & 031 \\
3 & 591 \\
10 & 549 \\
4 & 522 \\
& &
\end{tabular} & $\begin{array}{r}1 \\
0 \\
5 \\
10 \\
15 \\
20 \\
25 \\
30 \\
35 \\
40 \\
45 \\
0 \\
0\end{array}$ & $\begin{array}{l}4.1 \times 10^{-6} \\
4.2 \\
4.4 \\
4.6 \\
4.8 \\
5.0 \\
5.2 \\
5.5 \\
5.6 \\
5.8 \\
4.8 \\
\mid \\
14 \times 10^{-5} \\
14 \\
4.8 \times 10^{-6} \\
\mid\end{array}$ & $\begin{array}{l}4.13 \times 10^{-6} \\
4.21 \\
4.38 \\
4.58 \\
4.76 \\
4.93 \\
5.11 \\
5.49 \\
5.56 \\
5.69 \\
4.60 \\
4.75 \\
4.35 \\
4.69 \\
4.60 \\
4.64 \\
4.64 \\
1.38 \times 10^{-5} \\
1.38 \\
1.38 \\
4.96 \times 10^{-6} \\
4.95 \\
4.98 \\
4.99 \\
5.06 \\
5.13 \\
5.21 \\
5.22 \\
5.20 \\
5.15 \\
4.94 \\
4.84 \\
4.77 \\
4.44 \\
4.38 \\
3.56 \\
2.02 \\
2.08 \\
1.50 \\
1.60 \\
1.94 \\
5.51 \\
5.55 \\
5\end{array}$ & $\begin{array}{r}0.73 \\
.24 \\
-.47 \\
-.36 \\
-.74 \\
-1.44 \\
-1.65 \\
-.17 \\
-.76 \\
1.97 \\
-4.20 \\
-.97 \\
-.94 \\
-2.20 \\
-4.22 \\
-3.33 \\
-3.33 \\
-2.14 \\
-2.14 \\
-2.14 \\
3.32 \\
3.13 \\
3.82 \\
4.14 \\
5.37 \\
6.85 \\
8.47 \\
8.92 \\
8.37 \\
7.39 \\
2.92 \\
. .88 \\
-. .72 \\
-7.64 \\
-8.82 \\
-25.91 \\
-32.82 \\
-30.03 \\
-25.23 \\
-17.20 \\
29.65 \\
1.60 \\
.89 \\
1.25 \\
1.79 \\
1.96 \\
2.14 \\
1.42 \\
.30 \\
-1.65 \\
-4.64 \\
1.55 \\
-6.45\end{array}$ & $\begin{array}{l}\text { Speed pius } \\
\text { case } 5\end{array}$ \\
\hline
\end{tabular}


TABLE 7 - COMPARISON BETWEEN

PRESENT RESULT AND

EQUATION PROPOSED

BY HOUPERT

\begin{tabular}{|c|c|}
\hline Case & $H_{0}$ (Eq. (39)) \\
\hline & $H_{0}$ (Eq. (35)) \\
\hline 1 & 1.52 \\
2 & 1.50 \\
3 & 1.42 \\
4 & 1.38 \\
10 & 1.20 \\
11 & 1.54 \\
12 & 1.46 \\
13 & 1.40 \\
16 & 1.34 \\
17 & 1.34 \\
18 & 1.28 \\
19 & 1.28 \\
20 & 1.28 \\
21 & 1.37 \\
24 & 1.36 \\
30 & 1.35 \\
34 & 1.36 \\
37 & .969 \\
38 & .968 \\
39 & .927 \\
\hline
\end{tabular}




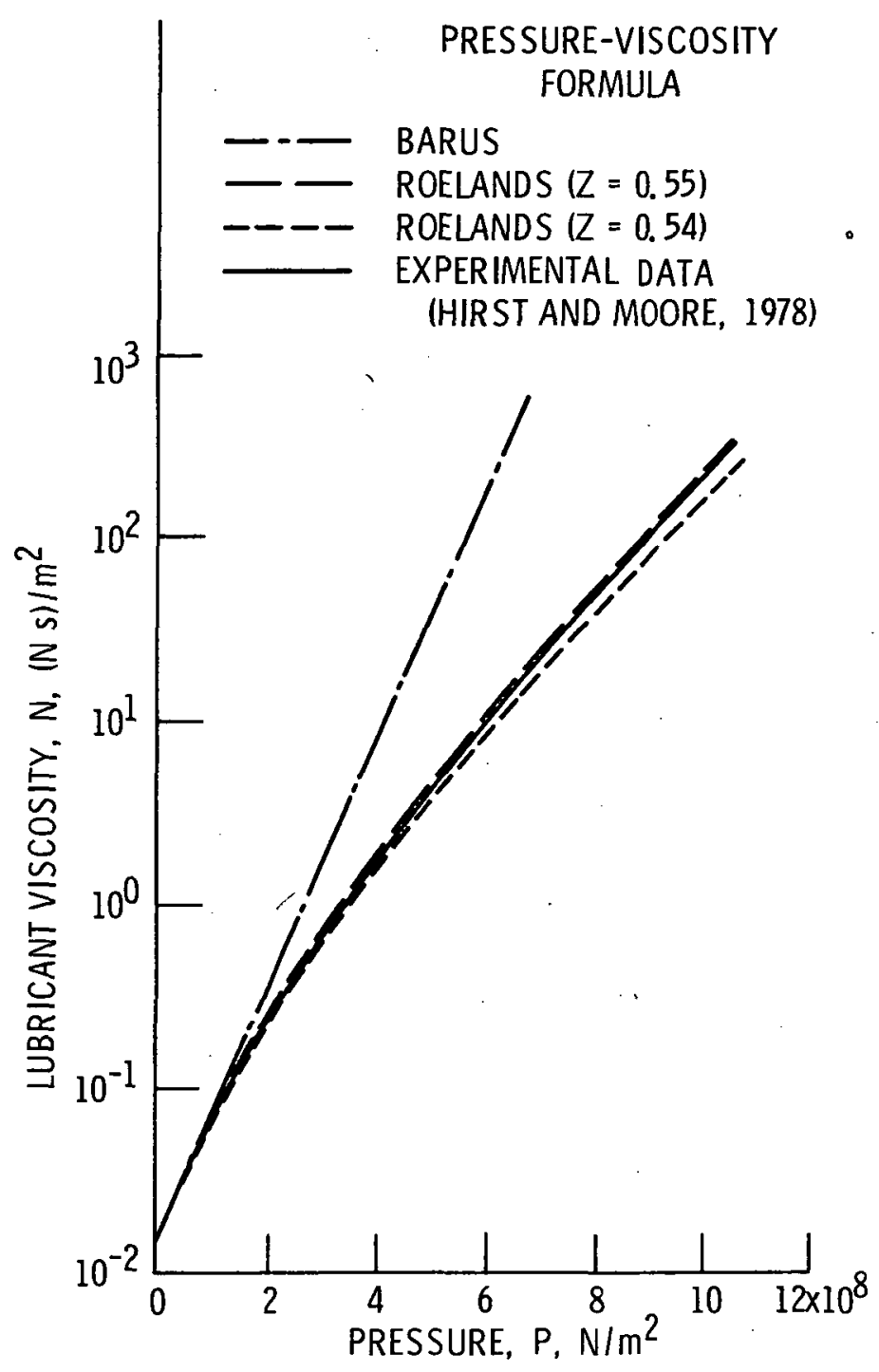

Fig. l Lubricant viscosity as a function of pressure. Lubricant, sebacate; temperature, $25^{\circ} \mathrm{C}$. 

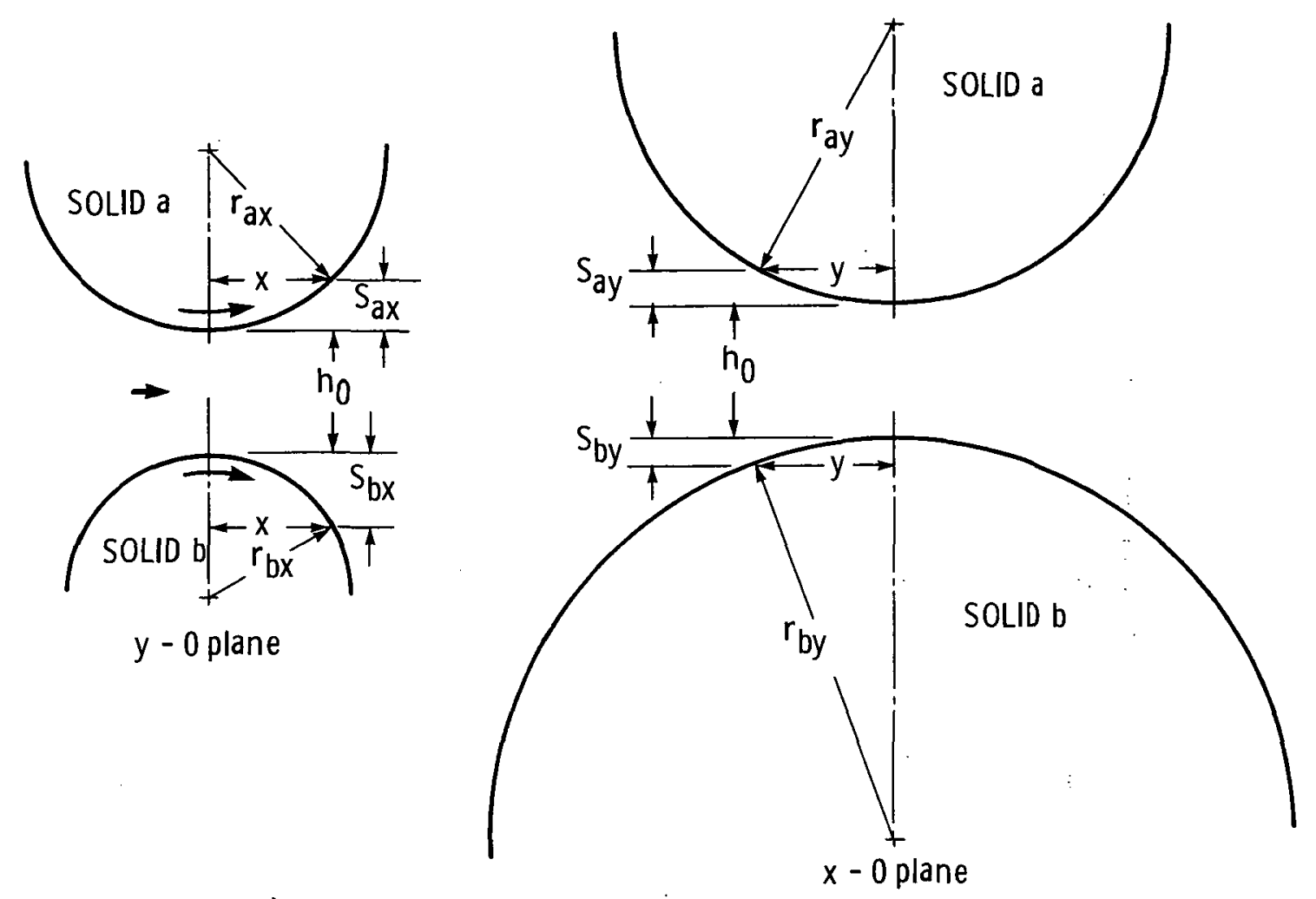

(a) Two rigid solids separated by a lubricant film.
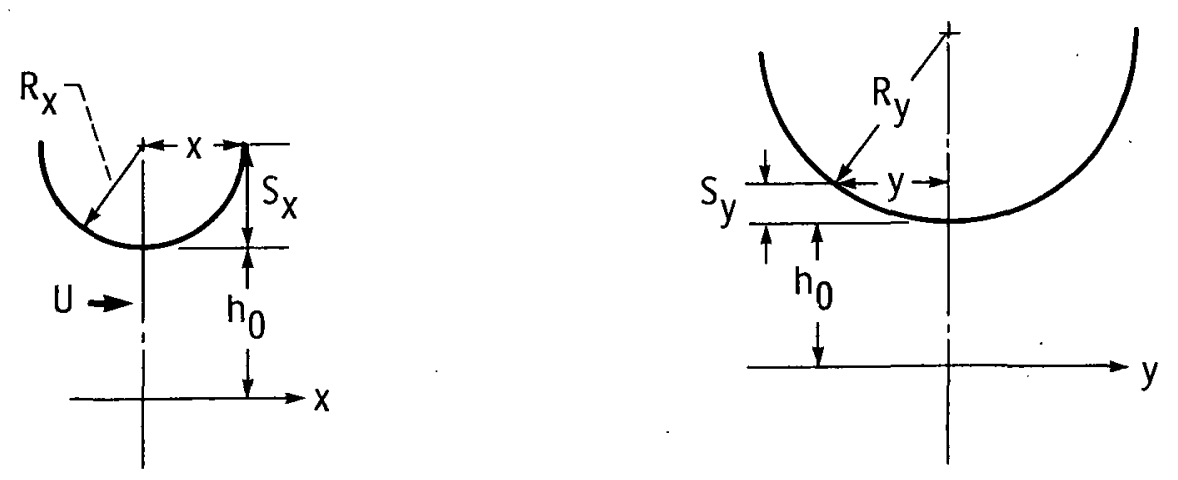

y - 0 plane

$x-0$ plane

(b) Equivalent system of a rigid solid near a plane separated by a lubricant film.

Fig. 2 Contact geometry. 


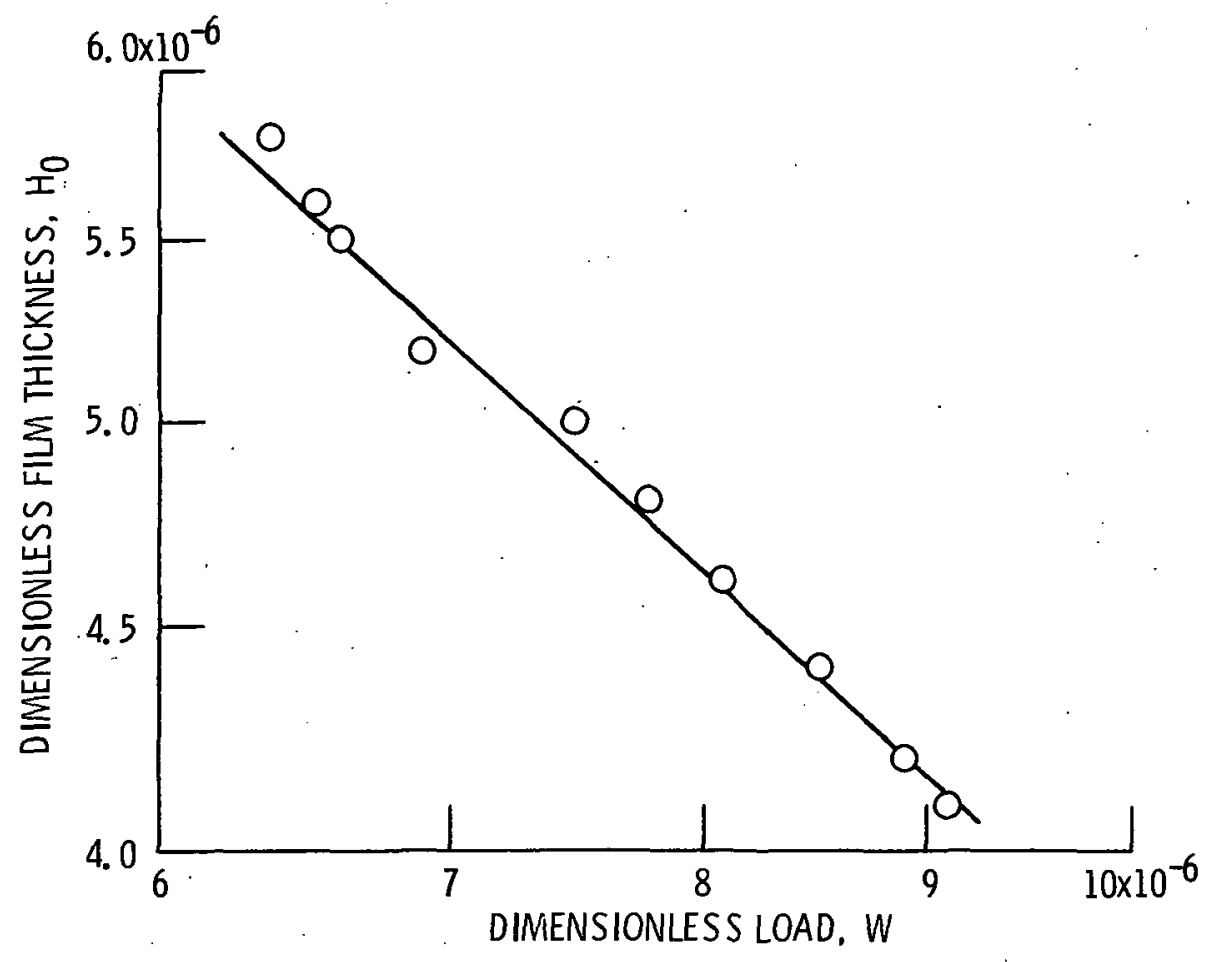

Fig. 3 Dimensionless minimium film thickness as a function of dimensionless load. 


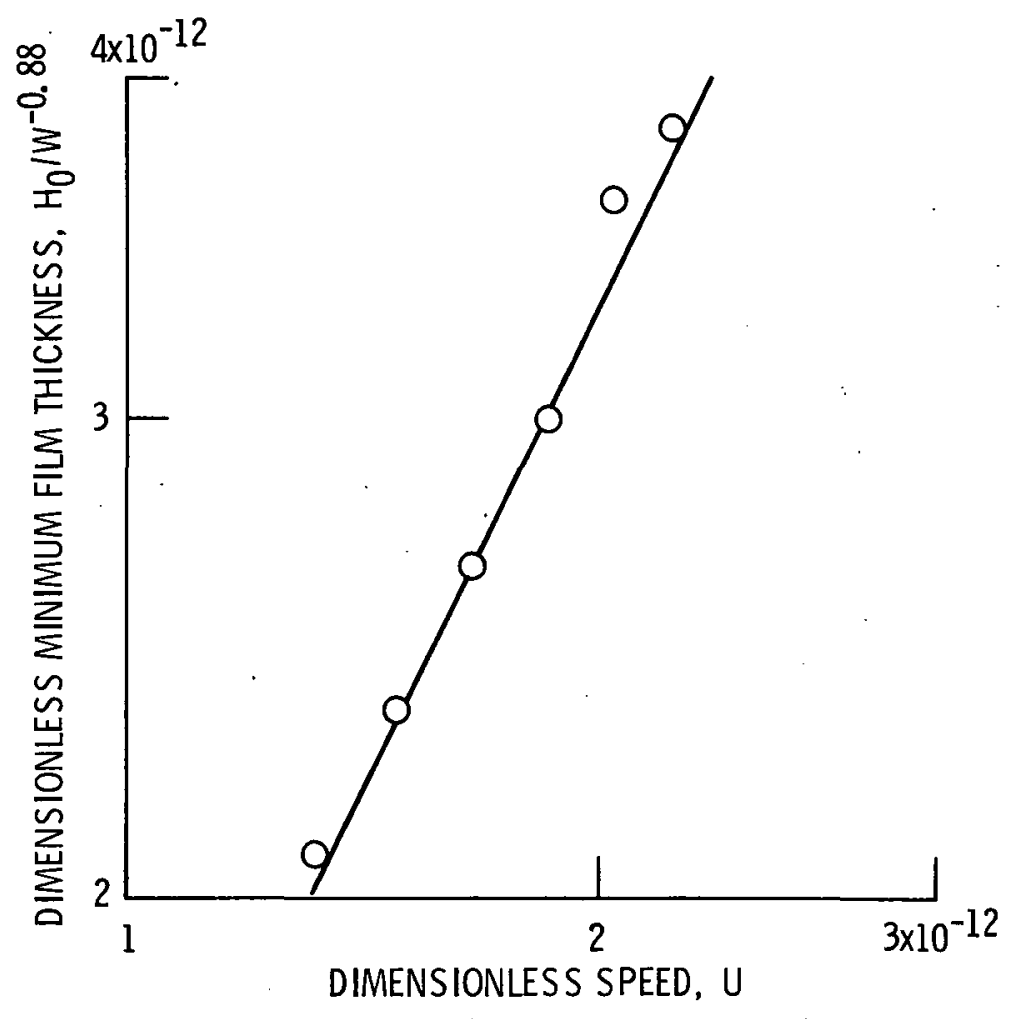

Fig. 4 Dimensionless minimum film thickness as a function of dimensionless speed. 


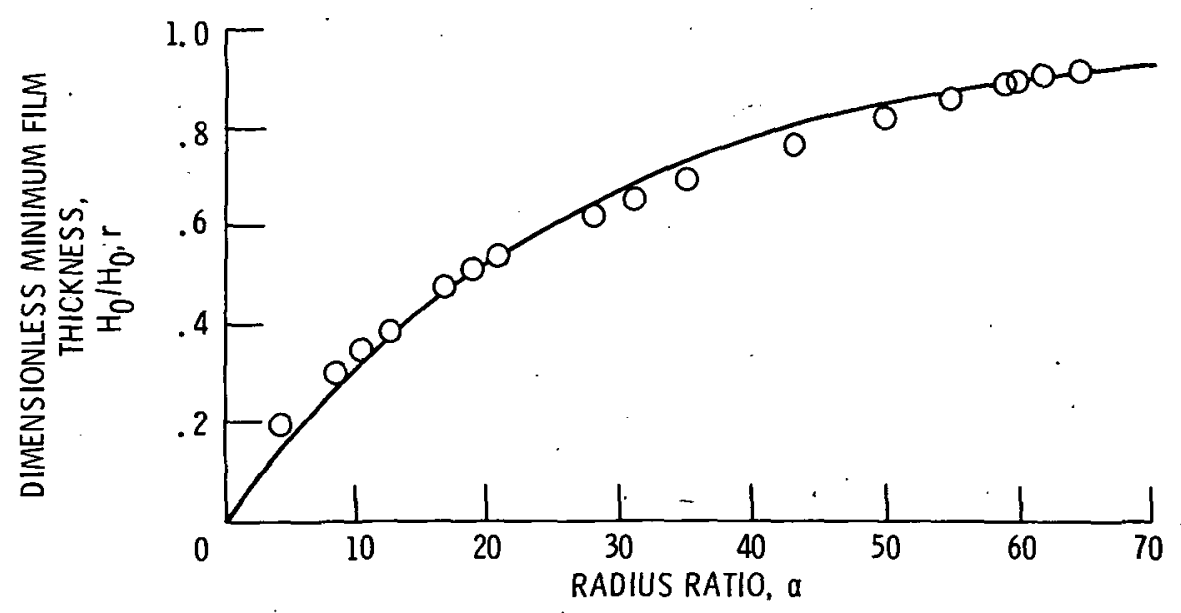

Fig. 5 Dimensionless minimum film thickness as a function of radius ratio.
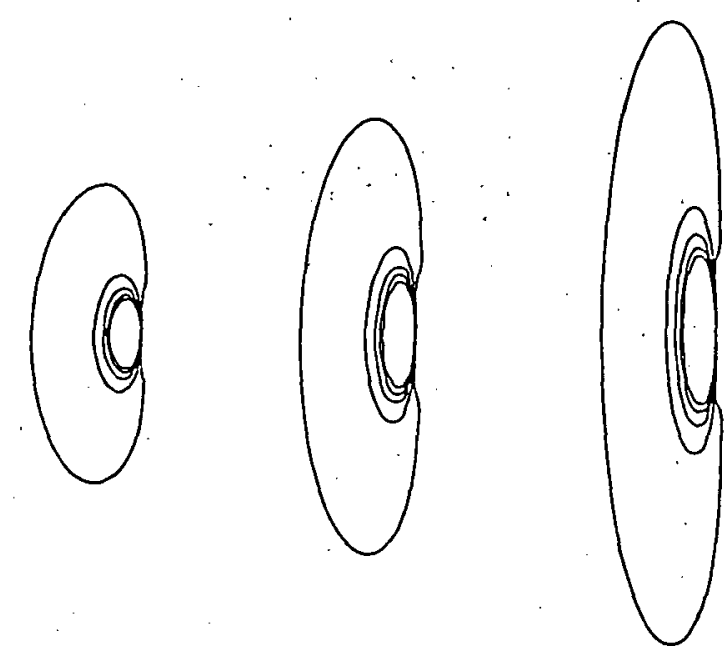
(a) $\alpha=4$.
(b) $\alpha=8$.
(c) $\alpha=16$.

Fig. 6 Pressure contour for three radius ratios $\alpha$. 


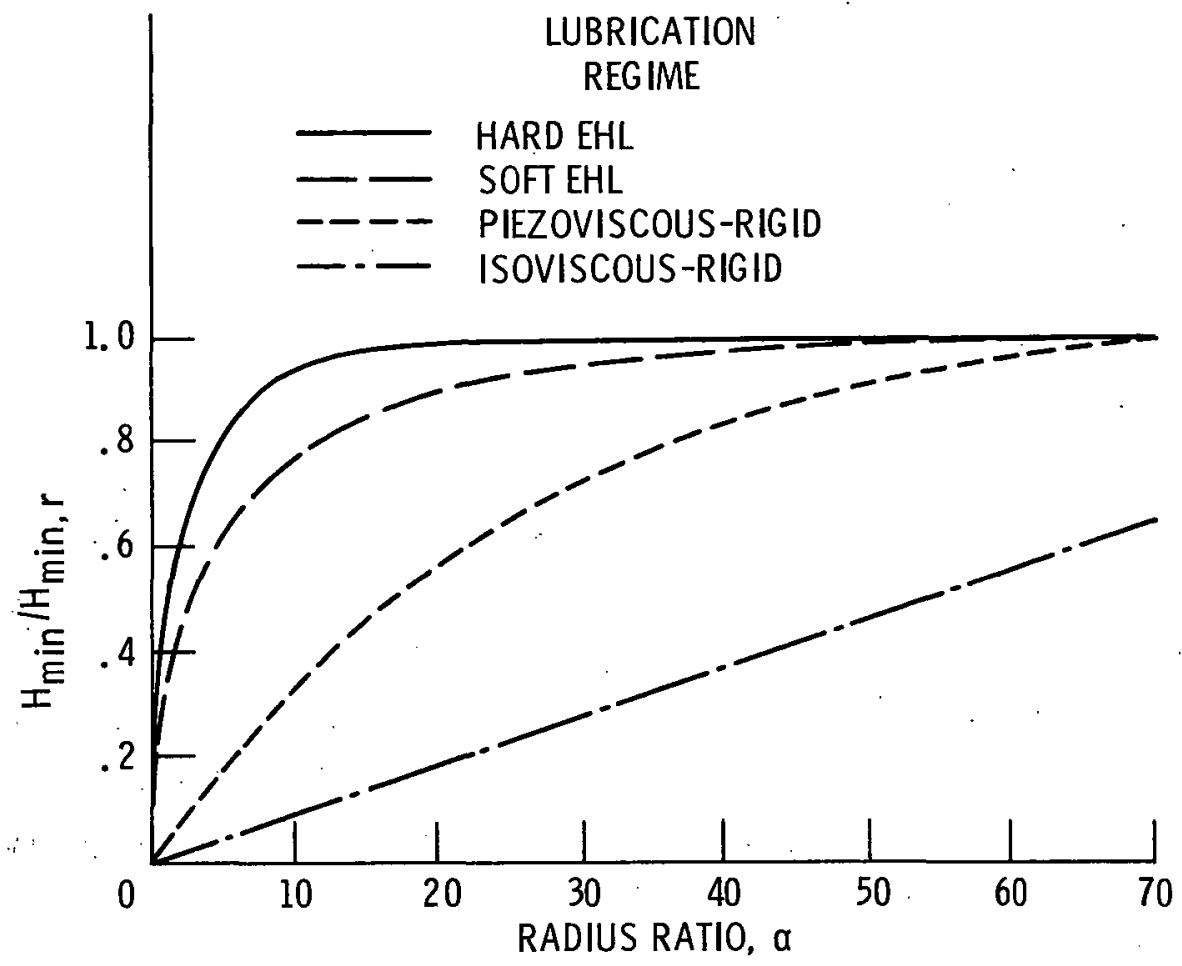

Fig. 7 Comparison of geometry effects in four lubrication regimes.

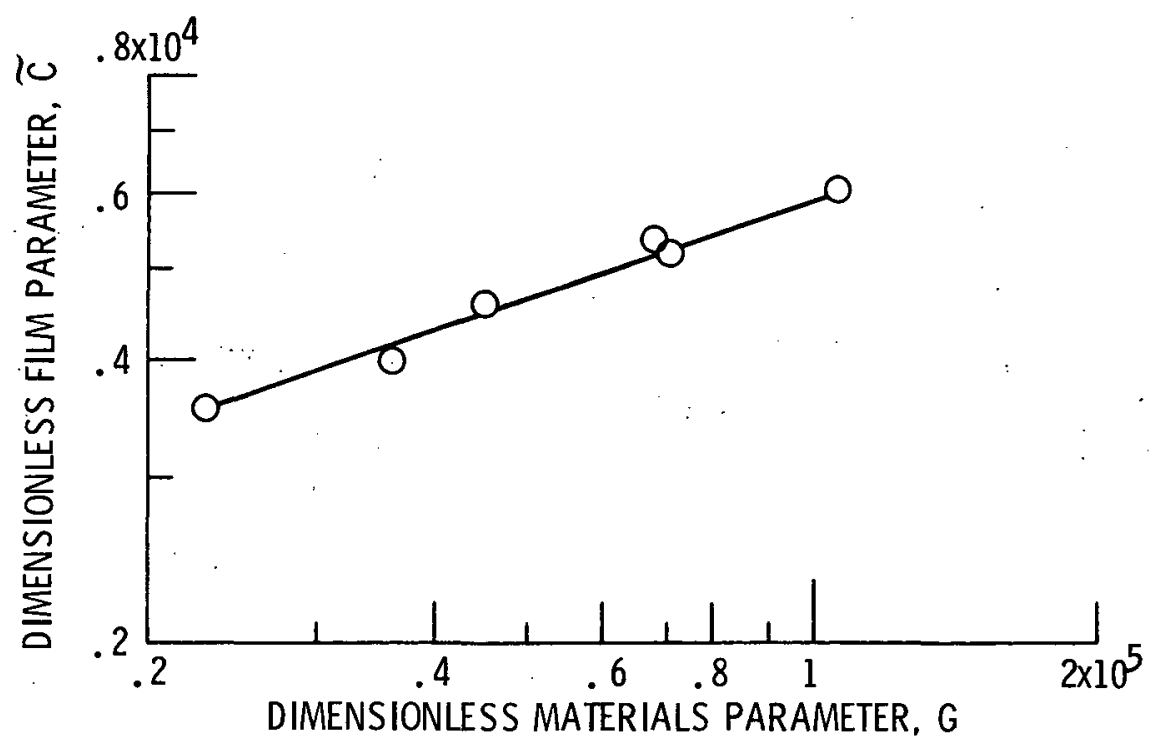

Fig. 8 Dimensionless film parameter as a function of materials parameter. 


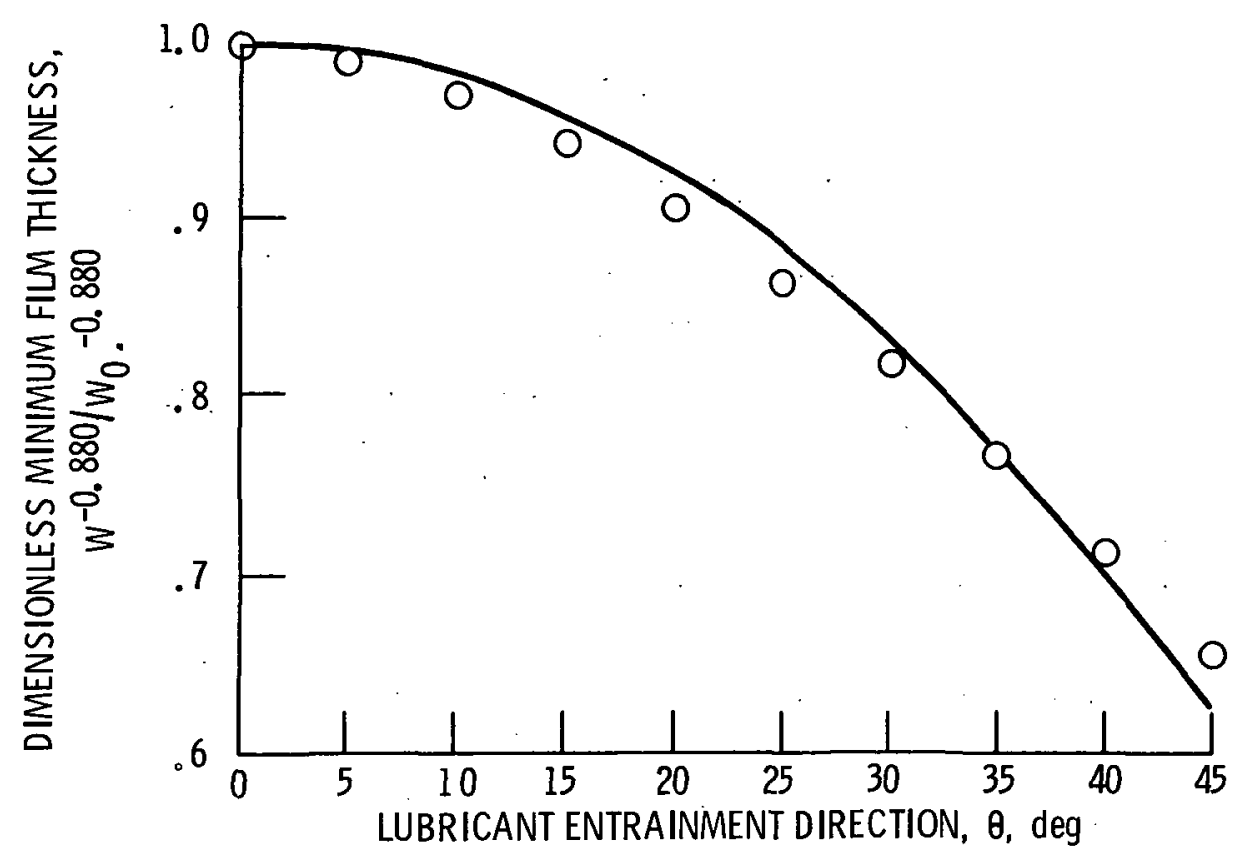

Fig. 9 Dimensionless minimum film thickness as a function of lubricant entrainment direction.

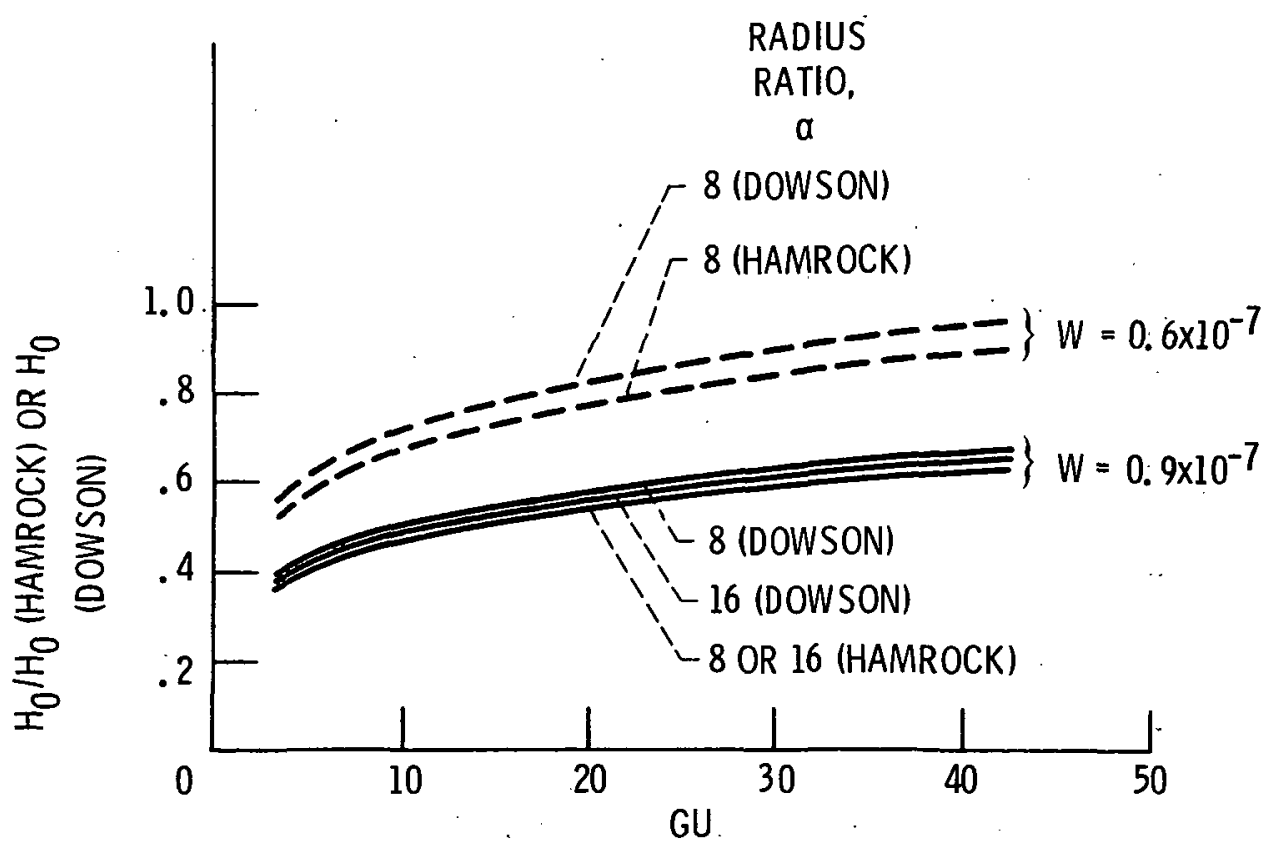

Fig. 10 Comparison between minimum film thickness formulas. 


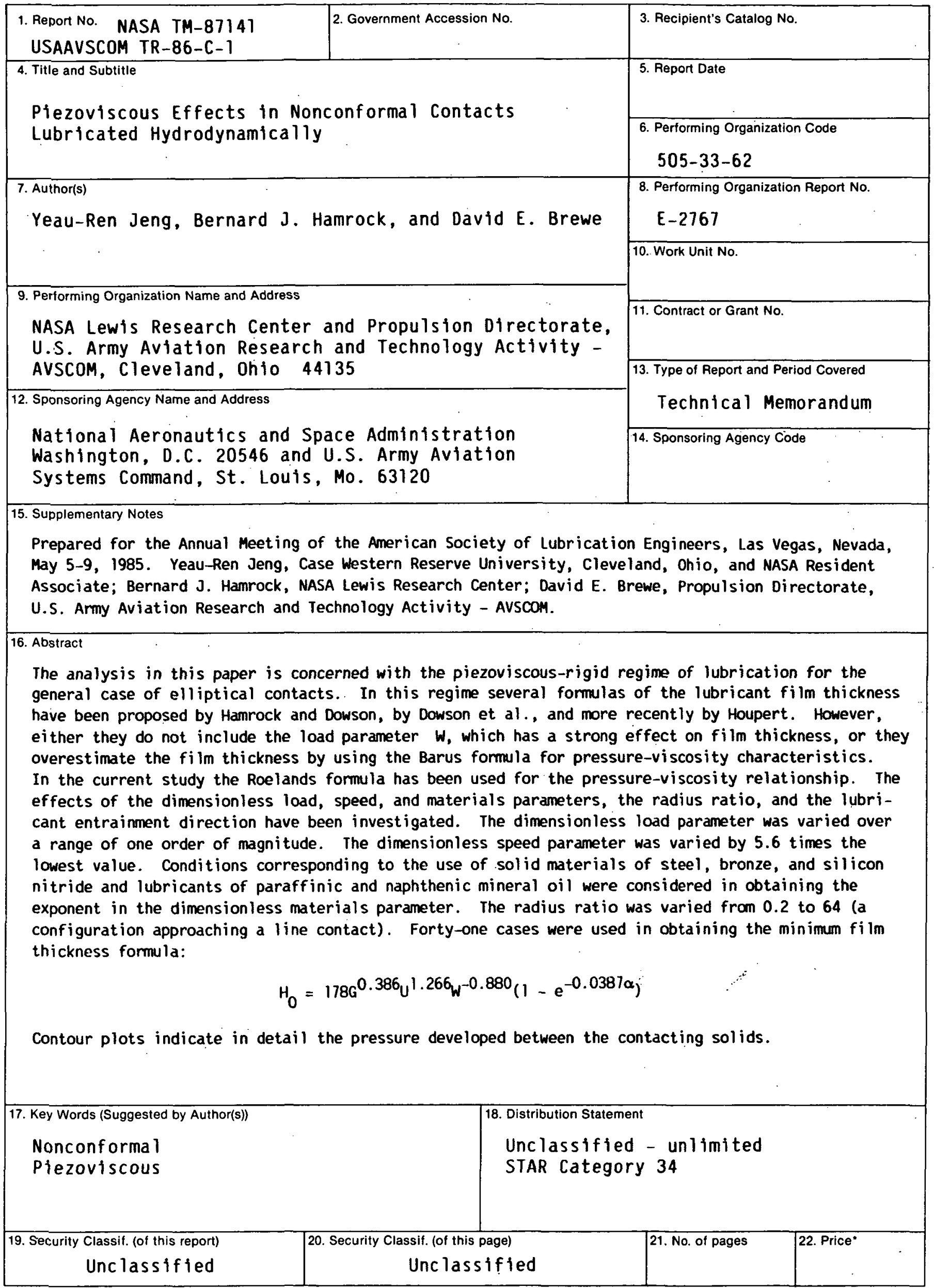

"For sale by the Nationai Technical Information Service, Springfield, Virginia 22161 
National Aeronautics and Space Administration

Lewis Research Center

Cleveland, Ohio 44135

Official Business

Penaly for Pitvate Use $\$ 300$
SECOND CLASS MAIL

ADORESS CORRECTION REQUESTED

Postage and Fees Paid

National Aeronautics and

Space Administration

NASA-451 